Check for updates

Cite this: Phys. Chem. Chem. Phys., 2019, 21, 4912

Received 23rd November 2018 , Accepted 4th February 2019

DOI: $10.1039 / \mathrm{c} 8 \mathrm{cp} 07231 \mathrm{k}$

rsc.li/pccp

\title{
Change of the kinetics of inclusion in cucurbit[7]uril upon hydrogenation and methylation of palmatine $\dagger$
}

\author{
Zsombor Miskolczy, (DD a Mónika Megyesi, (D) ${ }^{a}$ Orsolya Toke (D) $^{\mathrm{b}}$ and \\ László Biczók (iD *a
}

\begin{abstract}
The inclusion of protonated (-)-tetrahydropalmatine $\left(\mathbf{T H P}^{+}\right)$and dehydrocorydaline $\left(\mathbf{D H C}^{+}\right)$, natural alkaloids, in the cavity of cucurbit[7]uril was monitored in real time by a spectrofluorimetric method in water at various temperatures. Both guests produced 1:1 complexes in enthalpy controlled processes without any detectable intermediates. The tight entrance of CB7 imposed substantial steric hindrance for encapsulation making the entry into the host several orders of magnitude slower than diffusion. Despite the $\sim 6 \mathrm{~kJ} \mathrm{~mol}^{-1}$ lower activation enthalpy, the rate constant of THP $^{+}$ingression into CB7 was about 44 -fold smaller at $298 \mathrm{~K}$ than that of $\mathbf{D H C}^{+}$as a consequence of the considerably negative activation entropy of the former binding. The egression rates of the two studied alkaloids differed to a much lesser extent because the lower energy barrier of $\mathrm{THP}^{+}$release was almost compensated by the unfavourable activation entropy. In comparison with the kinetics of the reversible confinement of the palmatine parent compound, the presence of the methyl substituent on the aromatic heterocyclic ring in $\mathrm{DHC}^{+}$barely modified the rate constant of entry into CB7 but caused about 10 -fold increase in the dissociation rate at $298 \mathrm{~K}$.
\end{abstract}

\section{Introduction}

The non-covalent association of macrocyclic compounds has many potential biomedical applications in cellular imaging, photodynamic therapy, analyte sensing and drug and gene delivery. ${ }^{1,2}$ Inclusion complex formation is a versatile tool in supramolecular chemotherapy and in the creation of tailor-made functional nanostructures. ${ }^{3,4}$ The capability of synthetic host compounds to recognize amino acids, peptides, and protein surface elements can be used to modulate the interactions between proteins and to modify the activity of biomolecules. ${ }^{5,6}$ Among water-soluble biocompatible hosts, cucurbiturils $(\mathrm{CB} n)$ and their acyclic analogues have attracted particular attention due to their remarkable binding capability. ${ }^{7-10}$ The confinement in this type of molecular container improved the solubility, stability and bioactivity of guest molecules, ${ }^{11-14}$ which can be exploited to develop novel drug formulations. ${ }^{15-18}$ Because of the dynamic nature of complex formation, controlled release of the

\footnotetext{
${ }^{a}$ Institute of Materials and Environmental Chemistry, Research Centre for Natural Sciences, Hungarian Academy of Sciences, P.O. Box 286, 1519 Budapest, Hungary. E-mail:biczok.laszlo@ttk.mta.hu

${ }^{b}$ Laboratory for NMR Spectroscopy, Research Centre for Natural Sciences, Hungarian Academy of Sciences, P.O. Box 286, 1519 Budapest, Hungary

$\dagger$ Electronic supplementary information (ESI) available. See DOI: 10.1039/c8cp07231k
}

encapsulated molecule was achieved ${ }^{19}$ and $\mathrm{CB} n$ cavitands served as catalysts for 1,3-dipolar cycloaddition, hydrolysis, oxidation, and photoinduced reactions. ${ }^{20-23}$ The highly selective, strong binding of 1-adamantylamine-substituted substrates to cucurbit[7] uril-functionalized nanoparticles allowed facile non-covalent surface modification. ${ }^{24}$ The marked change of the fluorescent properties of guest molecules upon embedment in $\mathrm{CB} n^{25}$ was utilized for the development of indicator displacement assays and chemical sensors. ${ }^{26,27}$

Understanding the effect of the major factors controlling the rate of entry into and exit from the $\mathrm{CB} n$ cavity is of pivotal importance for the rational design of functional supramolecular assemblies and for gaining insight into the details of the dynamics of inclusion. Time-resolved measurements provided valuable information on pseudorotaxane formation. ${ }^{28-30}$ In a recent excellent review, Masson summarized the current state of knowledge on the kinetics of $\mathrm{CB} n$ complex formation. ${ }^{31}$ Although activation parameters provide unique information on the transition state and the energy barrier of reversible host-guest binding, very few such data have been reported. Despite its moderate binding affinity, cyclohexanediammonium produced a kinetically extraordinarily stable complex with cucurbit[6]uril (CB6) because the sterically strongly hindered dissociation had an activation enthalpy ${ }^{32}$ as high as $125.5 \mathrm{~kJ} \mathrm{~mol}^{-1}$. The slow exchange of 4-methylbenzylammonium ${ }^{33}$ and cyclohexylmethylammonium ${ }^{34}$ cations in CB6 allowed kinetic 
<smiles>COc1cc2c(cc1OC)[C@@H]1Cc3ccc(OC)c(OC)c3C[NH+](CC2)C1</smiles>

protonated

tetrahydropalmatine $\left(\mathrm{THP}^{+}\right)$

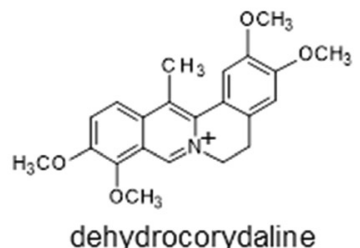

$\left(\mathrm{DHC}^{+}\right)$

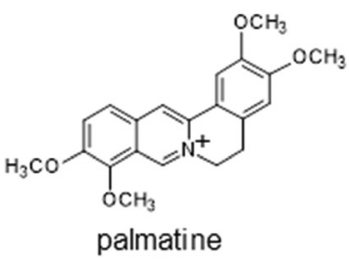

$\left(\mathrm{P}^{+}\right)$

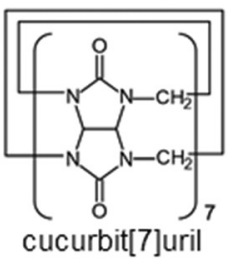

(CB7)

Scheme 1 Chemical structures of the guest and host compounds.

measurements by NMR spectroscopy. In $\mathrm{D}_{2} \mathrm{O}$ : formic acid $1: 1$ mixture, an activation enthalpy of 56.1 and $78.7 \mathrm{~kJ} \mathrm{~mol}^{-1}$ was obtained for the ingression of the former and latter cations, respectively, indicating that a substantial widening of the tight CB6 portals was needed for the penetration of these guests. ${ }^{33,34}$ The inclusion of an uncharged amine in CB6 and CB7 was more rapid than its protonated form because the embedment of the ammonium cation was retarded by exclusion complex formation, whereas the unprotonated amine directly entered the host. ${ }^{35,36}$ The encapsulation in the more spacious cucurbit[7]uril (CB7) was much faster than in CB6 and depended on the relative size of the guest and the openings of the host macrocycle. ${ }^{36-41}$ Further increase of the cavity size from CB7 to CB8 accelerated berberine inclusion $\sim 7$-fold but the rate of the process remained about 2 orders of magnitude slower than the diffusion-controlled limit. ${ }^{42}$ The study of the reversible binding between a dimethyl viologen-CB8 1:1 complex and electron-rich aromatic moieties tethered to a poly(ethylene glycol) chain demonstrated that the pressure and viscosity of the medium solely influence ingression rates whereas egression rates are sensitive mainly to the molecular structure of the electron-rich guest. ${ }^{43}$

Despite the key role of kinetic data in the rational design of $\mathrm{CB} n$ applications, limited knowledge has been gathered so far concerning the relationship between molecular structure and the rate constants of the inclusion in the $\mathrm{CB} n$ cavity. The main goal of the present study is to elucidate how the introduction of hydrogen atoms or a methyl substituent into palmatine influences the kinetic parameters of the embedment into and release from the $\mathbf{C B} 7$ cavitand. The chemical structures of the studied and parent compounds are shown in Scheme 1. The examined pharmacologically important natural alkaloids are the active ingredients of traditional Chinese herbal medicines. (-)-Tetrahydopalmatine is effective as an analgesic and sedative agent and has shown particular promise in the treatment of drug addiction. $^{44,45}$ Dehydrocorydaline exerts antinociceptive, antiallergic, and antitumor effects and protects the cardiovascular system. ${ }^{46}$

\section{Experimental}

(-)-Tetrahydopalmatine (THP ${ }^{+}$, Sigma-Aldrich) and dehydrocorydaline chloride ( $\mathbf{D H C}^{+}$, BOC Sciences) were used as received. The alkaloid concentrations were determined spectrophotometrically using the molar absorption coefficient of $5369 \mathrm{M}^{-1} \mathrm{~cm}^{-1}$ at $280 \mathrm{~nm}$ for protonated tetrahydopalmatine $\left(\mathbf{T H P}^{+}\right)$in aqueous
$\mathrm{HCl}$ solution of pH 4 and $22242 \mathrm{M}^{-1} \mathrm{~cm}^{-1}$ at $333 \mathrm{~nm}$ for $\mathbf{D H C}^{+}$ in water. High-purity $\mathbf{C B} 7$ was kindly provided by Dr Anthony I. Day (University of New South Wales, Canberra, Australia). Experiments were performed in double distilled water whose $\mathrm{pH}$ was set to 4 with $\mathbf{H C l}$ in the case of $\mathbf{T H P}^{+}$solutions.

The absorption spectra were obtained on an Agilent Technologies Cary60 spectrophotometer. Fluorescence spectra were taken on a Jobin-Yvon Fluoromax-P spectrofluorometer, whereas stoppedflow experiments were performed with the same instrument using an Applied Photophysics RX2000 rapid mixing accessory and a pneumatic drive. For each measurement, 10-20 kinetic traces were averaged. The temperature of the samples was varied with a Julabo F25-ED thermostat. The results of spectrophotometric and fluorescence titrations as well as stopped-flow measurements were analysed with homemade programs written in MATLAB 7.9. Isothermal calorimetric titrations were performed with a VP-ITC (MicroCal) instrument at $298 \mathrm{~K}$. All solutions were degassed prior to titration. The alkaloid solution $(\sim 300-600 \mu \mathrm{M})$ was injected stepwise $(10 \mu \mathrm{l}$ each) from the computer-controlled microsyringe at an interval of $270 \mathrm{~s}$ into $\sim 20-40 \mu \mathrm{M} \mathrm{CB7}$ solutions, while stirring at $300 \mathrm{rpm}$. The dilution heat, which was obtained by adding alkaloid solution into water under the same conditions as in the titration of $\mathbf{C B 7}$, was subtracted from the integrated heat evolved per injection. Data were analysed using the one-site binding model. The first data point was always removed. The measurements were repeated three times. NMR experiments were carried out on a $600 \mathrm{MHz}$ Varian NMR system spectrometer equipped with a $5 \mathrm{~mm}$ indirect detection ${ }^{1} \mathrm{H} /{ }^{31} \mathrm{P}-{ }^{15} \mathrm{~N} /{ }^{13} \mathrm{C}$ XYZ gradient probe. Measurements were performed in $0.1 \mathrm{mM} \mathrm{DCl} \mathrm{D}_{2} \mathrm{O}$ solutions at $298 \mathrm{~K}$. Solvent suppression was achieved by the PRESAT sequence. The ${ }^{1} \mathrm{H}$ chemical shifts were referenced externally to 2,2-dimethylsilapentane-5sulfonic acid.

\section{Results}

\section{$\mathrm{THP}^{+}$binding in $\mathrm{CB} 7$}

Because of its nonaromatic heterocyclic ring, $\mathbf{T H P}^{+}$had entirely different absorption and fluorescence spectra (Fig. 1) than palmatine $\left(\mathbf{P}^{+}\right) .{ }^{47}$ Fig. 1 presents the spectral changes upon alteration of $\mathrm{pH}$ in aqueous solution. As the site of protonation is not directly connected to the aromatic ring, only slight absorbance variation was observed. In contrast, more than 2-fold emission intensity enhancement appeared when the $\mathrm{pH}$ was decreased from 9 to 4 . A good match of the inflexion points of the sigmoid-shaped 

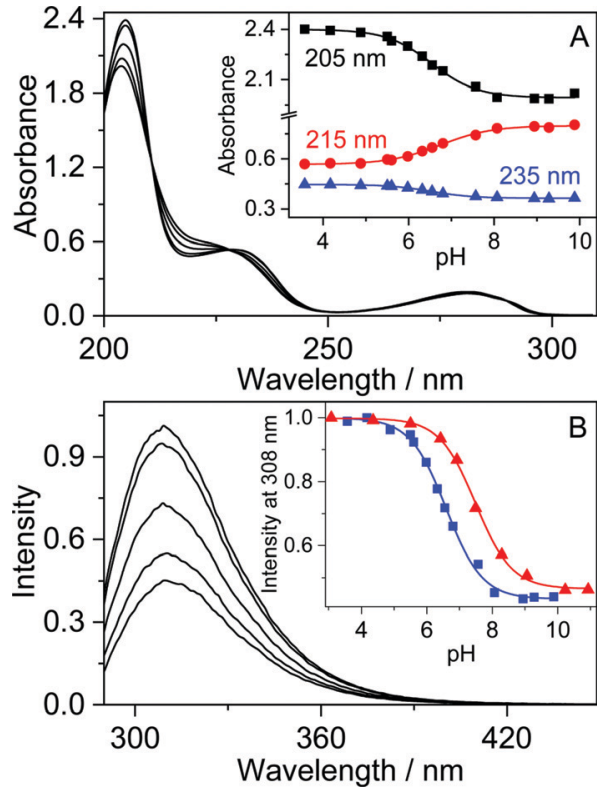

Fig. 1 Absorption (A) and fluorescence (B) spectra of $36 \mu \mathrm{M} \mathrm{THP}{ }^{+}$in water at $\mathrm{pH}$ 3.6, 5.5, 6.6, 7.6, and 9.3. Inset: (A) Absorbance at 205, 215, and $235 \mathrm{~nm}$ and (B) fluorescence intensity at $308 \mathrm{~nm}$ as a function of $\mathrm{pH}$ in water $(\square)$ and in $300 \mu \mathrm{M}$ CB7 aqueous solution ( $\mathbf{\Lambda}$ ) (excitation at $280 \mathrm{~nm}$ ).

titration curves was obtained by spectrophotometric and fluorescence methods. The results were analysed by nonlinear leastsquares fit of the following function:

$$
M=\frac{M_{0}-M_{\infty}}{1+\exp \left[\left(\mathrm{pH}-\mathrm{p} K_{\mathrm{a}}\right) \ln 10\right]}+M_{\infty}
$$

where $M_{0}$ and $M_{\infty}$ are the absorbances or fluorescence intensities at low and high pHs, respectively. The negative logarithm of the equilibrium constant of the dissociation of $\mathbf{T H P}^{+}$was found to be $\mathrm{p} K_{\mathrm{a}}=6.65$.

The absorption spectrum of $\mathbf{T H P}^{+}$barely varied upon addition of CB7 but the fluorescence titration curve shifted to larger pHs and $\mathrm{p} K_{\mathrm{a}}=7.54$ was obtained in the presence of $0.30 \mathrm{mM} \mathrm{CB7}$ (inset to Fig. 1B). The acidity diminution of $0.89 \mathrm{pH}$ units indicated the binding of $\mathbf{T H P}^{+}$in the nonpolar cavity of $\mathbf{C B} 7$. The hydrogen-bonding and ion-dipole interactions of the alkaloid $\mathrm{N}^{+}-\mathrm{H}$ bond with the carbonyl-laced portal of the host impeded proton release. The modification of the acidity of guests by inclusion complex formation has been reported for other amines, drugs, and dyes. ${ }^{48-51}$ As both free and $\mathbf{C B} 7$-encapsulated $\mathbf{T H P}^{+} \mathbf{S}$ are completely protonated at $\mathrm{pH} 4$, further experiments were performed under this condition.

The fluorescence quantum yield of $\mathbf{T H P}^{+}\left(\Phi_{\mathrm{F}}=0.14\right)$ and the fluorescence maximum $\left(\lambda_{\mathrm{F}}=310 \mathrm{~nm}\right)$ in the presence of $0.1 \mathrm{mM}$ $\mathrm{HCl}$ barely changed when ethanol was used as the solvent instead of water. Fig. 2 demonstrates that addition of $\mathbf{C B} 7$ to THP $^{+}$aqueous solution at $\mathrm{pH} 4$ brought about small fluorescence intensity diminution whereas the shape and maximum of the spectra did not alter. The scant variation of the fluorescent behaviour with the local environment arises from the lack of aromaticity of the fused heterocyclic ring in $\mathbf{T H P}^{+}$. The steep

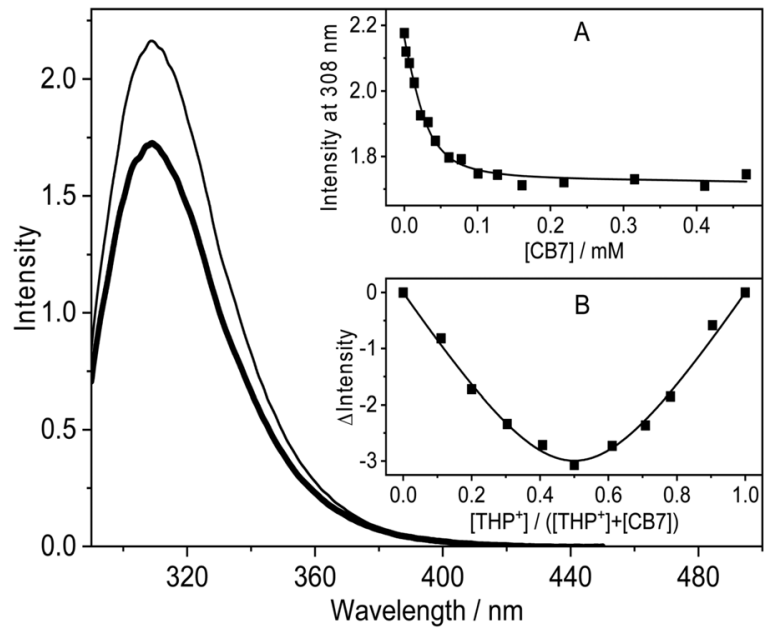

Fig. 2 Fluorescence spectra of $32 \mu \mathrm{M} \mathrm{THP}^{+}$at $\mathrm{pH} 4$ in water (thin line) and in $470 \mu \mathrm{M}$ CB7 aqueous solution (thick line). Inset: (A) Fluorescence intensity at $308 \mathrm{~nm}$ as a function of CB7 concentration at $298 \mathrm{~K}$ (excitation at $280 \mathrm{~nm}$ ). The line represents the results of the global analysis of the experimental data. (B) Job plot of the fluorescence intensity variation at $310 \mathrm{~nm}$ vs. the mole fraction of $\mathrm{THP}^{+}$. The total concentration $\left[\mathrm{THP}^{+}\right]+[\mathrm{CB} 7]=76 \mu \mathrm{M}$ is constant. The line shows the fitted curve assuming $K=1.2 \times 10^{5} \mathrm{M}^{-1}$ and $1: 1$ complexation.

initial emission intensity decline followed by the levelling off upon gradual increase of CB7 concentration (Fig. 2A) indicated complex formation. The fluorescence titration data could be fitted well assuming 1:1 binding. The global analysis of the results in the $290-388 \mathrm{~nm}$ domain provided $K=(1.2 \pm 0.2) \times$ $10^{5} \mathbf{M}^{-1}$ for the equilibrium constant of $\mathbf{T H} \mathbf{P}^{+}$confinement in CB7 at $298 \mathrm{~K}$. The equimolar association was confirmed by Job's continuous variation method. ${ }^{52}$ Fig. $2 \mathrm{~B}$ shows the difference in fluorescence intensity recorded at $310 \mathrm{~nm}$ in the absence and presence of $\mathbf{C B} 7$ as a function of the mole fraction of $\mathbf{T H P} \mathbf{P}^{+}$. The total concentration of reactants was kept constant $(76 \mu \mathrm{M})$. The minimum appeared at $\left[\mathbf{T H P}^{+}\right] /\left(\left[\mathbf{T H} \mathbf{P}^{+}\right]+[\mathbf{C B} 7]\right)=0.5$ implying $1: 1$ binding stoichiometry.

To gain insight into the structural characteristics of the THP ${ }^{+}-\mathbf{C B} 7$ complex, we turned to NMR spectroscopy. Because of the lower sensitivity of this method, much more concentrated (0.5 mM) alkaloid solutions had to be used than in absorption and fluorescence spectroscopic experiments. The $\mathbf{T H P}^{+}$signals in the absence and presence of $\mathbf{C B 7}$ were assigned on the basis of combined ${ }^{1} \mathrm{H}-{ }^{1} \mathrm{H}$ TOCSY, ROESY, and natural abundance ${ }^{13} \mathrm{C}$-HSQC measurements. The aromatic region of the ${ }^{1} \mathrm{H}$ NMR spectra exhibited the most characteristic spectral differences between the free and bound $\mathbf{T H P}^{+}$(Fig. S1 in the ESI $\dagger$ ). The twodimensional ${ }^{1} \mathrm{H}-{ }^{13} \mathrm{C}$-HSQC spectrum of unbound $\mathbf{T H P}^{+}$is depicted in Fig. S2 of the ESI. $\dagger$ The peak doubling observed in the free $\mathbf{T H P}^{+}$spectrum is related to a slow inversion at the cationic nitrogen giving rise to two $\mathbf{T H P}^{+}$species with slightly different chemical environments for the ring protons. The resonances corresponding to the aromatic ring protons of the tetrahydroisoquinolinium moiety (at positions 11 and 12) display substantial shifts to lower frequencies demonstrating the encapsulation of this segment of the guest molecule in CB7. In contrast, the resonance of the proton at position 1 is shifted downfield 


\section{(-)-Tetrahydopalmatine}

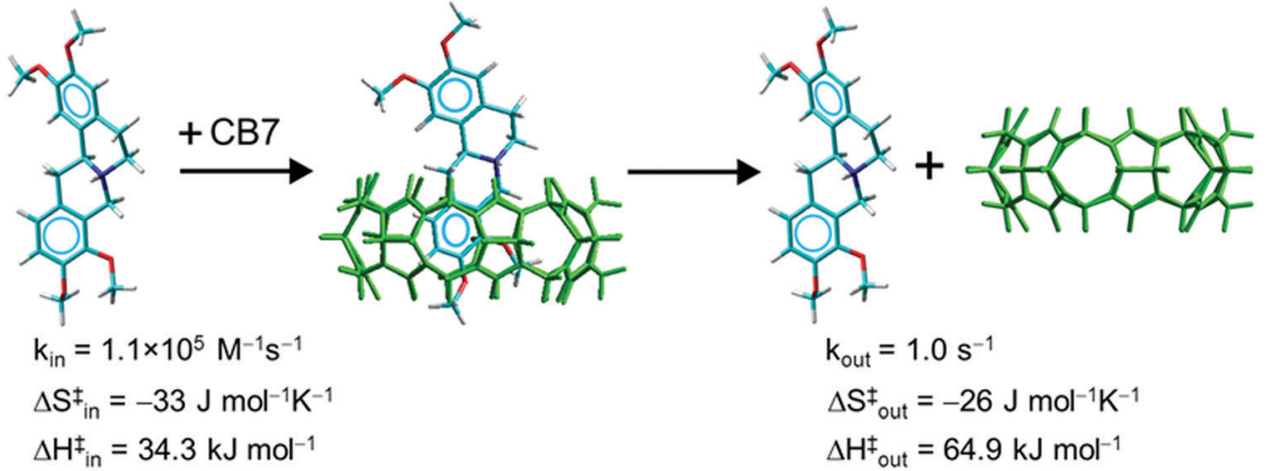

Dehydrocorydaline

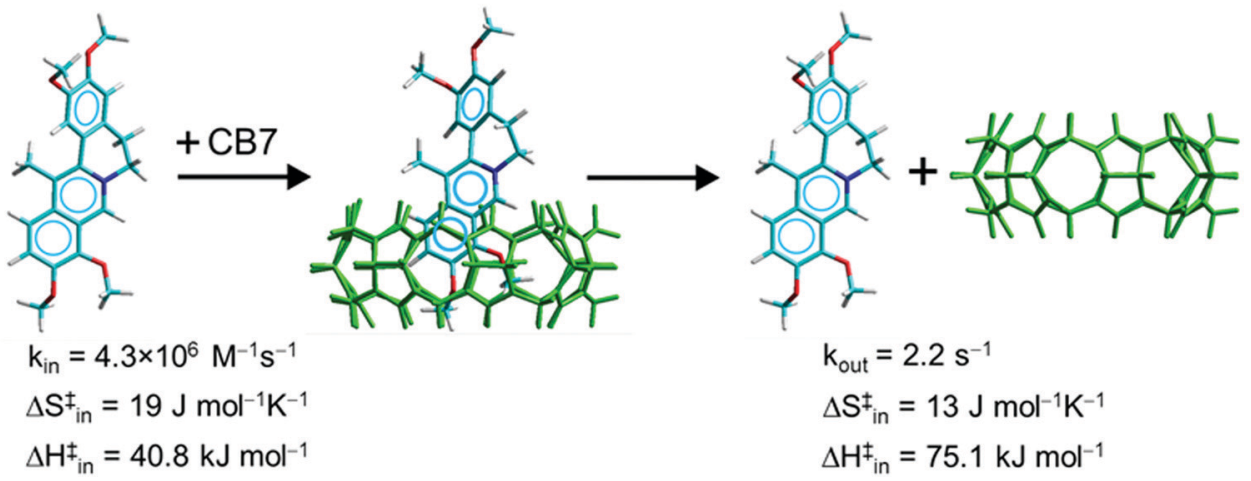

Scheme 2 Rate constants at $298 \mathrm{~K}$ and activation parameters.

indicating the deshielding effect of the carbonyl groups of CB7 outside the cavity. The proton at position 4 resonates at nearly the same frequency as in free $\mathbf{T H P}^{+}$suggesting negligible interaction with the host. The most probable structure of the $\mathbf{T H P}^{+}-\mathbf{C B} 7$ complex is presented in the upper panel of Scheme 2 (vide supra).

To reveal the thermodynamics of association, isothermal calorimetric measurements were carried out. As a representative example, Fig. 3 shows the enthalpogram recorded for the titration of $\mathbf{C B} 7$ in water with $\mathbf{T H P}^{+}$solution at $\mathrm{pH} 4$. Because of the decrease of the number of the free macrocycles, the evolved heat gradually decreased upon successive alkaloid additions. An inflexion point appeared at equimolar mixing ratio confirming $1: 1$ inclusion. Nonlinear least-squares fit of the titration data resulted in $K=(1.1 \pm 0.2) \times 10^{5} \mathrm{M}^{-1}$ for the binding constant at temperature $T=298 \mathrm{~K}$, in good agreement with the corresponding value derived from fluorescence measurements (vide supra). For the enthalpy change of complexation, $\Delta H=-30.6 \pm$ $1.7 \mathrm{~kJ} \mathrm{~mol}^{-1}$ was calculated. Using these quantities, $\Delta S=-6 \pm$ $5 \mathrm{~J} \mathrm{~mol}^{-1} \mathrm{~K}^{-1}$ was obtained for the entropy change of $\mathbf{T H P}^{+}-\mathbf{C B} 7$ formation on the basis of the equation: $\Delta S=\Delta H / T+R \ln K$, where $R$ stands for the gas constant.

The decrease of fluorescence quantum yield of $\mathbf{T H P}^{+}$upon confinement in CB7 was exploited to monitor the kinetics of the reversible host-guest binding in real time. Fig. 4A displays typical fluorescence intensity (I) decay at $310 \mathrm{~nm}$ after rapid mixing of the constituents. The signal reached a plateau when

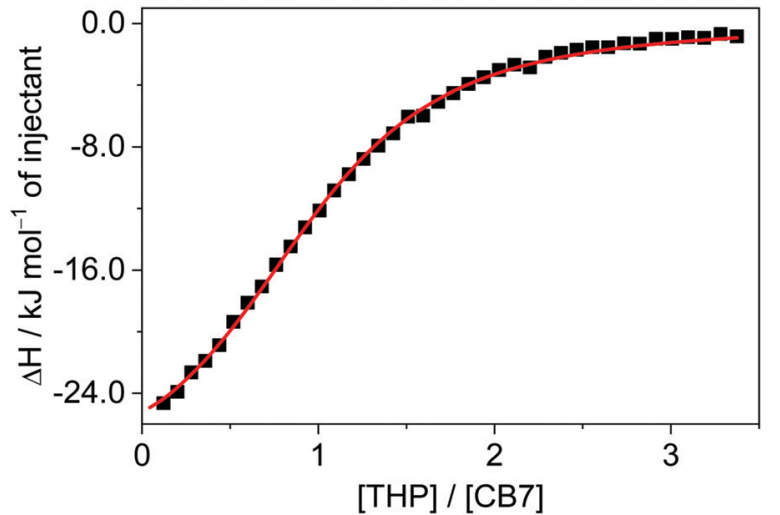

Fig. 3 Integrated heat released per injection for the titration of $38.3 \mu \mathrm{M}$ CB7 by $610 \mu \mathrm{M}$ THP $^{+}$solution at $298 \mathrm{~K}$ and $\mathrm{pH} 4$. The line represents the best fit with a one-site binding model.

equilibrium was established. In the case of a simple $1: 1$ encapsulation, the kinetics of $I$ alteration is defined as follows:

$$
\begin{aligned}
\frac{\mathrm{d} I}{\mathrm{~d} t} & =a_{\mathrm{F}} \frac{\mathrm{d}\left[\mathrm{THP}^{+}\right]}{\mathrm{d} t}+a_{\mathrm{c}} \frac{\mathrm{d}\left[\mathrm{THP}^{+}-\mathrm{CB} 7\right]}{\mathrm{d} t} \\
& =\left(a_{\mathrm{F}}-a_{\mathrm{C}}\right)\left\{k_{\text {in }}\left[\mathrm{THP}^{+}\right][\mathrm{CB} 7]-k_{\text {out }}\left[\mathrm{THP}^{+}-\mathrm{CB} 7\right]\right\}
\end{aligned}
$$

where $k_{\text {in }}$ and $k_{\text {out }}$ denote the rate constants of ingression and egression, and $a_{\mathrm{F}}$ and $a_{\mathrm{C}}$ are constants linearly proportional to 

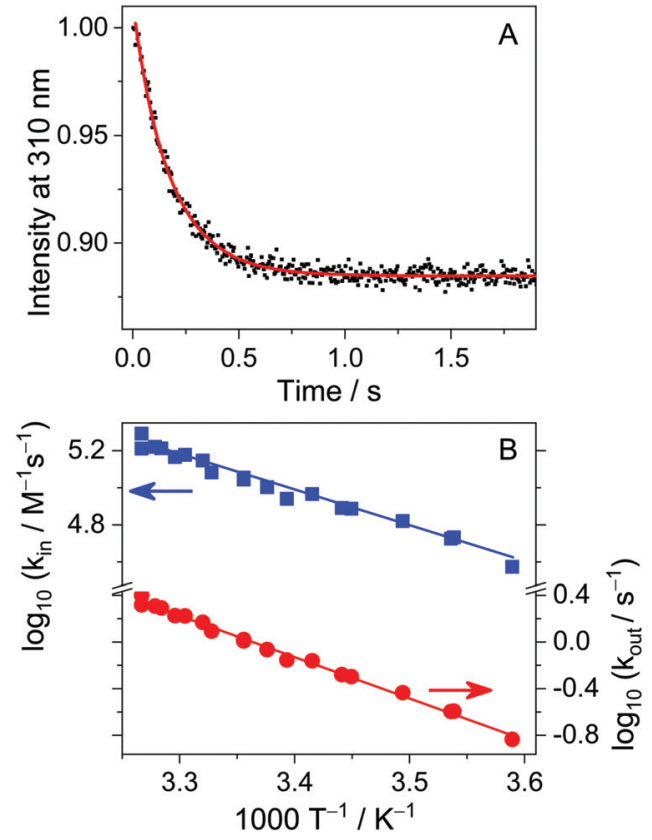

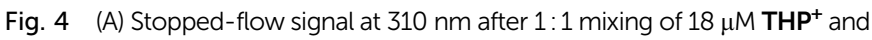
$85 \mu \mathrm{M} \mathrm{CB7}$ aqueous solutions at $298 \mathrm{~K}$. Excitation at $280 \mathrm{~nm}$. The line shows the result of the nonlinear least-squares analysis. (B) Arrhenius plots of the rate constants of inclusion in $\mathbf{C B 7}$ and the dissociation of the $\mathrm{THP}^{+}-\mathbf{C B 7}$ complex.

the fluorescence efficiencies of free and complexed $\mathbf{T H P}^{+}$at the monitoring wavelength, respectively. As the data were normalized to $I=1$ at $t=0 \mathrm{~s}, a_{\mathrm{C}} / a_{\mathrm{F}}$ was used as a fitting parameter in addition to the rate constants $k_{\text {in }}$ and $k_{\text {out }}$. The numerical solution of differential eqn (2) was fitted to the results of stopped-flow experiments. At $298 \mathrm{~K}, k_{\text {in }}=(1.1 \pm 0.1) \times 10^{5} \mathrm{M}^{-1} \mathrm{~s}^{-1}$ and $k_{\text {out }}=1.0 \pm 0.1 \mathrm{~s}^{-1}$ was calculated for the rate constants of $\mathbf{T H P}^{+}$entry into and exit from $\mathbf{C B 7}$ as mean values of the results obtained at various concentrations.

To determine the activation parameters, the rate constants were measured by the stopped-flow technique at various temperatures. Fig. 4B presents the logarithm of $k_{\text {in }}$ and $k_{\text {out }}$ as a function of the reciprocal temperature. Nonlinear leastsquares analysis of the data with the Arrhenius equation $k=$ $A \exp (-E / R T)$ provided the activation energies $(E)$ and $A$ factors. The excellent fit of the kinetic traces assuming simple 1:1 association indicates that no intermediate is produced in the course of $\mathbf{T H P}^{++}-\mathbf{C B 7}$ complex formation within the time scale of the stopped-flow experiment ( $>10 \mathrm{~ms}$ ). Hence, the transition state theory can be applied to understand the meaning of the Arrhenius parameters. From the Eyring-Polanyi equation, the following relationships can be derived for the standard entropy $\left(\Delta S^{\ddagger}\right)$ and enthalpy $\left(\Delta H^{\ddagger}\right)$ of activation:

$$
\begin{gathered}
\Delta H^{\ddagger}=E-R T \\
\Delta S^{\ddagger}=R \ln \left(A \frac{h}{\kappa e k_{\mathrm{B}} T}\right)
\end{gathered}
$$

where $e, k_{\mathrm{B}}$, and $h$ represent the base of the natural logarithm, and Boltzmann and Planck constants, respectively. The transmission coefficient $(\kappa)$ is assumed to be equal to one. The calculated kinetic parameters are summarized in Scheme 2, whereas the kinetic and thermodynamic quantities of host-guest complexation are combined in Table 1.

\section{$\mathrm{DHC}^{+}$inclusion in $\mathrm{CB} 7$}

To unravel the effect of methylation in position 13 of palmatine on the kinetics of encapsulation in CB7, stopped-flow experiments were performed with $\mathbf{D H C}{ }^{+}$. A previous study showed that the 1:1 embedment of this alkaloid in CB7 brought about substantial fluorescence intensity enhancement and the emission maximum of the complex appeared at $476 \mathrm{~nm} .{ }^{54}$ The alteration of the absorption and fluorescence spectra upon gradual increase of $\mathbf{C B} 7$ concentration is presented in Fig. S3 in the ESI. $\dagger$ The sensitivity of the fluorescence properties to the local environment is characteristic of protoberberine alkaloids possessing an aromatic isoquinolinium moiety. ${ }^{53,55}$ We examined the inclusion in real time by monitoring the rise of the emission intensity after fast mixing of $\mathbf{D H C}^{+}$and $\mathbf{C B} 7$ solutions. Low reactant concentrations $(\sim 0.26 \mu \mathrm{M})$ were used to decelerate the bimolecular ingression

Table 1 Kinetic and thermodynamic parameters for the reversible binding of alkaloids in CB7

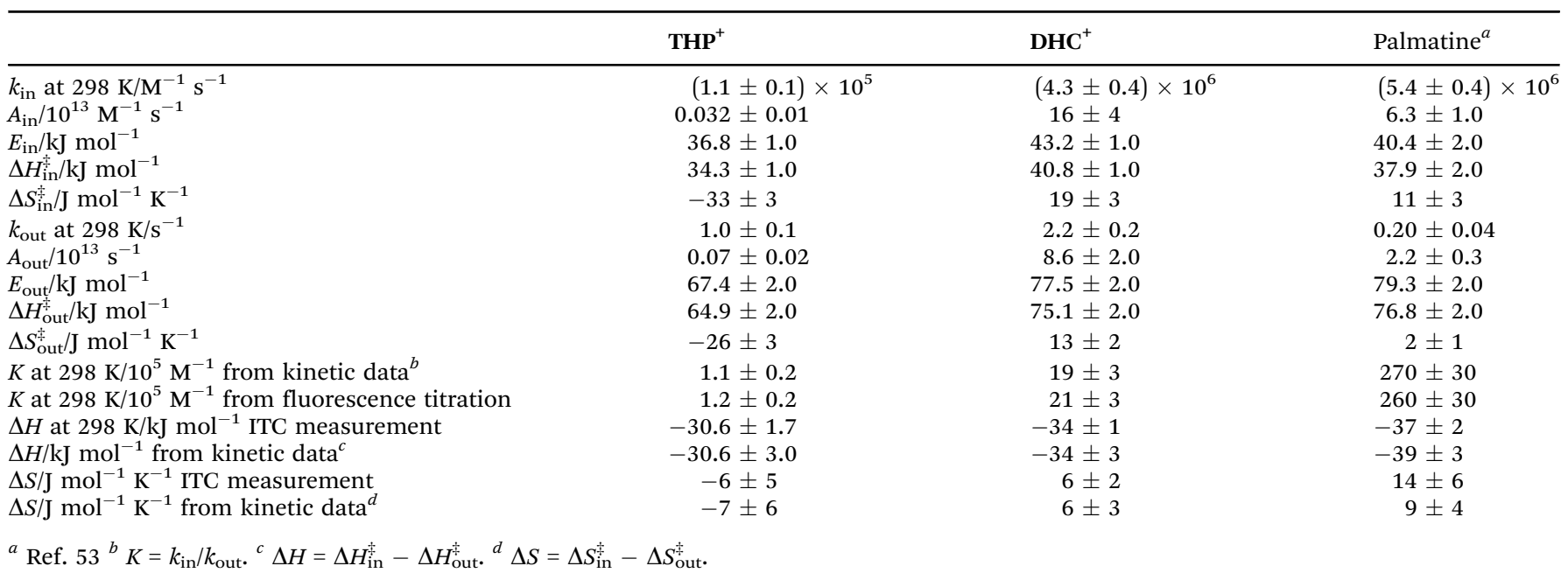



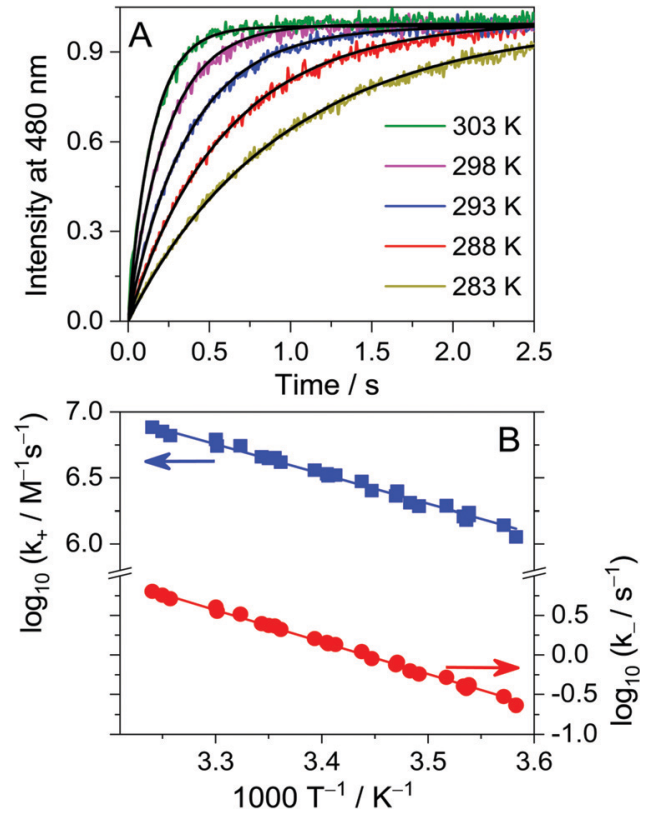

Fig. 5 (A) Rise of fluorescence intensity at $480 \mathrm{~nm}$ in $0.24 \mu \mathrm{M} \mathrm{DHC}^{+}$and $0.27 \mu \mathrm{M}$ CB7 solution after rapid mixing of the reactants at various temperatures. Excitation occurred at $335 \mathrm{~nm}$. The signals were normalized at the intensity in the equilibrium. (B) Logarithm of the rate constants for the entry of $\mathbf{D H C}^{+}$into $\mathbf{C B 7}$ and the dissociation of the $1: 1$ complex as a function of reciprocal temperature. The lines represent the results of the nonlinear fit of the Arrhenius equation on a logarithmic scale.

into a conveniently measurable time range. Fig. 5A presents the normalized fluorescence intensity versus time traces at various temperatures. Since the free $\mathbf{D H C}^{+}$emits negligible fluorescence, the intensity growth directly reflects the augmentation of $\mathbf{D H C}^{+}-\mathbf{C B} 7$ complex concentration. The substantial change of the initial slopes with temperature indicates that a considerable activation barrier hinders the $\mathbf{D H C}^{+}$entry into $\mathbf{C B 7}$. The kinetic results were analysed as described for $\mathbf{T H} \mathbf{P}^{+}-\mathbf{C B} 7$ complex formation (vide supra). The Arrhenius plots of the derived $k_{\text {in }}$ and $k_{\text {out }}$ values are displayed in Fig. 5B, whereas the calculated activation parameters are given in Scheme 2 and Table 1 . The ratio of the rate constants of ingression and egression provided $K=k_{\text {in }} / k_{\text {out }}=(2.2 \pm 0.3) \times$ $10^{6} \mathrm{M}^{-1}$ for the binding constant of $\mathbf{D H C}^{+}$in CB7. Practically the same value $\left(K=(2.1 \pm 0.3) \times 10^{6} \mathrm{M}^{-1}\right)$ was obtained from the results of spectrophotometric and fluorescence titrations plotted in Fig. S3 in the ESI. $\dagger$

Table 1 includes the thermodynamic parameters of hostguest complexation determined directly by isothermal titration calorimetry together with the values calculated as the difference of the corresponding activation parameters of ingression and egression. The integrated heat released per injection of $330 \mu \mathrm{M}$ DHC $^{+}$into $22.8 \mu \mathrm{M} \mathrm{CB7}$ solution as a function of reactant molar ratio is shown in Fig. 6. The location of the inflection point close to $\left[\mathbf{D H C}^{+}\right] /[\mathbf{C B} 7]=1$ verifies the $1: 1$ association stoichiometry. The thermodynamic quantities calculated from the enthalpogram are shown in Table 1 and the obtained binding constant $\left(K=(1.9 \pm 0.3) \times 10^{6} \mathrm{M}^{-1}\right)$ is in accordance with those found by other methods (vide supra).

\section{Discussion}

The kinetic and thermodynamic parameters of the host-guest binding of $\mathbf{T H P}^{+}$and $\mathbf{D H C}^{+}$in $\mathbf{C B 7}$ are compared in Table 1 with those published for palmatine $\left(\mathbf{P}^{+}\right)$complexation. ${ }^{53}$ The introduction of a methyl substituent in position 13 slightly affects the rate constant of entry into $\mathbf{C B} 7$ because the increase of the activation barrier $\left(\Delta H_{\mathrm{in}}^{+}\right)$is compensated by the activation entropy $\left(\Delta S_{\mathrm{in}}^{ \pm}\right)$enhancement. The presence of the methyl group in $\mathbf{D H C}^{+}$alters the structure of the activated complex resulting in $\sim 3 \mathrm{~kJ} \mathrm{~mol}^{-1}$ higher transition state enthalpy than in the case of $\mathbf{P}^{+}$ingression. The high $\Delta H_{\mathrm{in}}^{+}$values for both alkaloids indicate constrictive binding. As the portals of $\mathbf{C B 7}$ are narrower than the cavity, an elliptical modification of the carbonyl rim of CB7 is the prerequisite for the inclusion. The positive $\Delta S_{\text {in }}^{\ddagger}$ suggests that the activated complex resembles the free components more than the final host-guest associate. This is in agreement with the Hammond-Leffler postulate, which also predicts that the geometry of the transition state is more similar to the reactants than to the products in an exothermic process. The larger $\Delta S_{\text {in }}^{\text {f for }}$ DHC $^{+}$compared with $\mathbf{P}^{+}$probably originates from the looser binding of the former guest in the transition state. Positive $\Delta S_{\text {in }}^{\ddagger}$ is found for $\mathbf{D H C} \mathbf{C}^{+}$and $\mathbf{P}^{+}$alike implying that the limitation of the degrees of freedom in the transition state is overcompensated by the entropy gain due to release of water from the hydrate shell of the reactants.

The activation entropy of egression $\left(\Delta S_{\text {out }}^{\ddagger}\right)$ is also positive for DHC $^{+}$but close to zero for $\mathbf{P}^{+}$. According to NMR spectra, ${ }^{54}$ DHC $^{+}$is less deeply embedded in the $\mathbf{C B 7}$ cavity than $\mathbf{P}^{+}$because of the steric hindrance caused by its methyl substituent. Therefore, more water remains in the host interior and the guest is more hydrated in $\mathbf{D H C}^{+}-\mathbf{C B} 7$ than in $\mathbf{P}^{+}-\mathbf{C B} 7$. As a consequence, the structural rearrangement of the former complex into the transition state is accompanied by lesser changes in solvation. Therefore, the entropy gain stemming from the partial release of the guest from CB7 upon reaching the weakly bound transition state is counterbalanced to a smaller extent by the entropy loss originating from the coordination of water molecules in the case of $\mathbf{D H C} \mathbf{C}^{+}-\mathbf{C B} 7$ dissociation.

The shallower inclusion of $\mathbf{D H C}^{+}$in $\mathbf{C B 7}$ than its unmethylated analogue leads to less negative enthalpy change $(\Delta H)$ upon

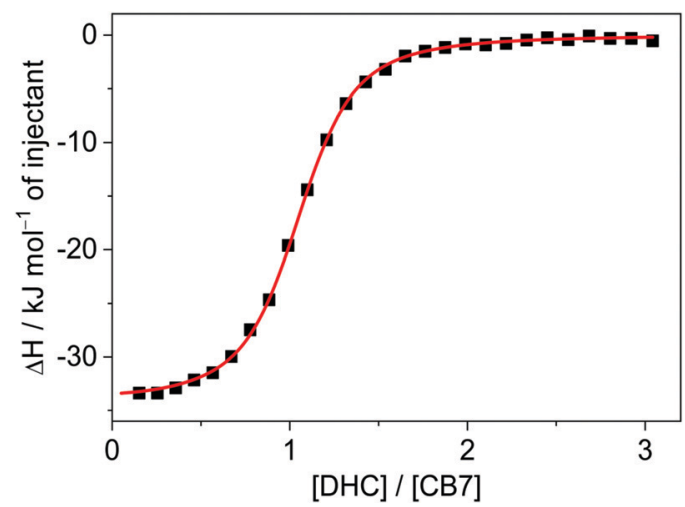

Fig. 6 Enthalpogram for the titration of $22.8 \mu \mathrm{M} \mathrm{CB} 7$ with $330 \mu \mathrm{M} \mathrm{DHC}$ aqueous solution at $298 \mathrm{~K}$. 
complex formation and more than one order of magnitude smaller binding constant (Table 1). The entropy term has similar and small contribution to the driving force of host-guest association of both alkaloids. The activation enthalpy of dissociation $\left(\Delta H_{\text {out }}^{\ddagger}\right)$ also barely differs because the lower exothermicity of $\mathbf{D H C}^{+}$confinement almost compensates the more substantial activation energy of the entry into CB7. The $\sim 10$-fold faster egression for $\mathrm{DHC}^{+}$than for $\mathbf{P}^{+}$at $298 \mathrm{~K}$ originates from the combined effects of the larger $\Delta S_{\text {out }}^{\ddagger}$ and slightly smaller $\Delta H_{\text {out }}^{\ddagger}$ case.

The hydrogenation of $\mathbf{P}^{+}$also significantly alters the kinetics of inclusion complex formation. Despite its lower activation enthalpy, $\mathbf{T H P}^{+}$enters into $\mathbf{C B 7}$ about 50-fold slower than its parent compound at $298 \mathrm{~K}$ and the process has $\sim 60000$ fold lower rate constant than the diffusion-controlled limit ${ }^{56}$ $\left(k_{\text {diff }}=6.5 \times 10^{9} \mathrm{M}^{-1} \mathrm{~s}^{-1}\right)$. The surprisingly slow association is ascribed to the substantial negative activation entropy $\left(\Delta S_{\text {in }}^{+}=\right.$ $\left.-32 \mathrm{~J} \mathrm{~mol}^{-1} \mathrm{~K}^{-1}\right)$. The negative $\Delta S_{\mathrm{in}}^{ \pm}$, which has not been observed for any other $\mathbf{C B} 7$ complexation, may indicate that the entropy gain arising from the change of hydration cannot overwhelm the reduction of the degrees of freedom within the tightly bound transition state. Hydrogen bonding of the $\mathrm{N}^{+}-\mathrm{H}$ moiety of $\mathbf{T H P}^{+}$to the oxygen(s) located at the opening of CB7 may strengthen the interaction between the components of the activated complex. In addition, the flexible character of free $\mathbf{T H P}^{+}$ owing to its two fused nonaromatic rings allows the limitation of more degrees of freedom than in the activated complex of the much more rigid $\mathbf{P}^{+}$.

Kinetic results for 4-methylbenzylammonium ion assembly with cucurbit[6]uril (CB6) demonstrated the existence of both exclusion and inclusion complexes. ${ }^{57}$ Nau and coworkers suggested that primary ammonium cations first bind to the portal of CB6 producing an exclusion complex in which the organic moiety is still located in the bulk solvent. Then the hydrophobic part of the guest slips into the CB6 cavity in a "flip-flop" manner. ${ }^{34,35}$ When the more spacious CB7 served as a host, such an association pathway was found only for 2-aminoanthracenium embedment but the anthracene moiety of this guest could also directly enter into $\mathbf{C B 7} .^{36}$ Exclusion complex formation seems to be possible when the ammonium group and the hydrophobic moiety are located at the two ends of the guest. No evidence was found for association into the exclusion complex in the case of $\mathbf{T H P}^{+}$binding to $\mathbf{C B} 7$.

The activation entropy of $\mathbf{T H} \mathbf{P}^{+}$exit from $\mathbf{C B} 7\left(\Delta S_{\text {out }}^{\ddagger}\right)$ is also considerably negative because the transition to the tightly bound transition state allows relatively small entropy gain. Moreover, the coordination of water molecules upon partial release of $\mathbf{T H} \mathbf{P}^{+}$also contributes to the unfavourable $\Delta S_{\text {out }}^{\ddagger}$. The remarkably negative $\Delta S_{\text {out }}^{\ddagger}$ lessens the Arrhenius $A_{\text {out }}$ factor but the almost $12 \mathrm{~kJ} \mathrm{~mol}^{-1}$ smaller activation enthalpy $\left(\Delta H_{\text {out }}^{\ddagger}\right)$ for $\mathbf{T H} \mathbf{P}^{+}$dissociation relative to that of $\mathbf{P}^{+}$exit from $\mathbf{C B 7}$ exerts an opposite effect on the egression rate constant. As a consequence, $\mathbf{T H} \mathbf{P}^{+}$is released from CB7 only 5 times faster than $\mathbf{P}^{+}$. The combined effects of the lower $\Delta H_{\mathrm{in}}^{\ddagger}$ and the less exothermic complexation causes the substantial $\Delta H_{\text {out }}^{\ddagger}$ diminution going from $\mathbf{P}^{+}-\mathbf{C B} 7$ to $\mathbf{T H P} \mathbf{P}^{+}-\mathbf{C B} 7$ because $\Delta H_{\text {out }}^{\ddagger}$ is the difference of $\Delta H_{\text {in }}^{\ddagger}$ and the enthalpy change upon binding $(\Delta H)$. The less negative $\Delta H$ for the latter complex is assigned to the lack of aromaticity in the heterocyclic ring of the guest. This unfavourably influences the binding enthalpy owing to the following: (i) because no charge delocalization can take place, the nitrogen of the guest becomes more hydrophilic and larger energy is needed for the reorganization of its hydrate shell, (ii) dipole $-\pi$ interaction between $\mathbf{C B 7}$ and the heterocycle cannot stabilize $\mathbf{T H P}^{+}-\mathbf{C B 7}$, and (iii) the nonplanar molecular structure and the increased number of hydrogens may make the hostguest binding sterically less advantageous. The more than two orders of magnitude decrease of the association constant upon the replacement of $\mathbf{P}^{+}$with $\mathbf{T H} \mathbf{P}^{+}$results not only from the diminution of the exothermicity of complexation but also from the unfavourable entropy changes.

\section{Conclusions}

Even minor variations in the molecular structure, such as addition of hydrogens or a methyl substituent considerably alter the formation and dissociation kinetics of inclusion complexes when constrictive binding takes place. The determination of activation parameters is necessary for a deeper understanding of the relationship between molecular structure and the rate constants of entry into and exit from the host because opposite changes in $\Delta H^{\ddagger}$ and $\Delta S^{\ddagger}$ often mask the trends. Such a phenomenon appears for $\mathbf{T H P}^{+}$ingression into $\mathbf{C B} 7$ whose rate constant is 50 -fold lower than that of the corresponding process of $\mathbf{P}^{+}$because the beneficial effect of $\Delta H_{\mathrm{in}}^{\ddagger}$ diminution is overwhelmed by the inclusion deceleration arising from the significantly negative $\Delta S_{\mathrm{in}}^{\ddagger}$. A tightly bound transition state is produced in the course of entry into CB7 when the guest contains a nonaromatic heterocycle with localized charge, such as $\mathbf{T H} \mathbf{P}^{+}$. On the other hand, hostguest interaction is weak in the transition state when the positive charge of the nitrogen is distributed throughout the aromatic rings of the guests like in $\mathbf{P}^{+}$and $\mathbf{D H C} \mathbf{C}^{+}$.

\section{Conflicts of interest}

There are no conflicts of interest to declare.

\section{Acknowledgements}

This work was supported by the National Research, Development and Innovation Office (NKFIH, Grant K123995), the BIONANO GINOP-2.3.2-15-2016-00017 project, and the János Bolyai Research Scholarship Program of the Hungarian Academy of Sciences (to ZM).

\section{References}

1 X. Ma and Y. Zhao, Chem. Rev., 2015, 115, 7794-7839.

2 G. Ghale and W. M. Nau, Acc. Chem. Res., 2014, 47, 2150-2159.

3 J. Zhou, G. Yu and F. Huang, Chem. Soc. Rev., 2017, 46, 7021-7053.

4 H. Zhu, L. Shangguan, B. Shi, G. Yu and F. Huang, Mater. Chem. Front., 2018, 2, 2152-2174. 
5 S. van Dun, C. Ottmann, L.-G. Milroy and L. Brunsveld, J. Am. Chem. Soc., 2017, 139, 13960-13968.

6 C. Hou, X. Zeng, Y. Gao, S. Qiao, X. Zhang, J. Xu and J. Liu, Isr. J. Chem., 2018, 58, 286-295.

7 E. Masson, in Comprehensive Supramolecular Chemistry II, ed. J. L. Atwood, Elsevier Inc., 2017, vol. 5, pp. 21-45.

8 N. J. Wheate and C. Limantoro, Supramol. Chem., 2016, 28, 849-856.

9 S. Ganapati and L. Isaacs, Isr. J. Chem., 2018, 58, 250-263.

10 C. B. Rodell, J. E. Mealy and J. A. Burdick, Bioconjugate Chem., 2015, 26, 2279-2289.

11 S. Li, J. Y.-W. Chan, Y. Li, D. Bardelang, J. Zheng, W. W. Yew, D. P.-C. Chan, S. M. Y. Lee and R. Wang, Org. Biomol. Chem., 2016, 14, 7563-7569.

12 Z. Miskolczy, M. Megyesi, G. Tárkányi, R. Mizsei and L. Biczók, Org. Biomol. Chem., 2011, 9, 1061-1070.

13 Z. Miskolczy and L. Biczók, J. Phys. Chem. B, 2011, 115, 12577-12583.

14 H. S. El-Sheshtawy, S. Chatterjee, K. I. Assaf, M. N. Shinde, W. M. Nau and J. Mohanty, Sci. Rep., 2018, 8, 13925.

15 H. Yin and R. Wang, Isr. J. Chem., 2018, 58, 188-198.

16 D. H. Macartney, in Comprehensive Supramolecular Chemistry II, ed. J. L. Atwood, Elsevier, Oxford, 2017, vol. 1, pp. 479-494.

17 A. I. Day and J. G. Collins, in Supramolecular Chemistry: From Molecules to Nanomaterials, ed. P. A. Gale and J. W. Steed, John Wiley \& Sons, Ltd, 2012.

18 K. I. Kuok, S. Li, I. W. Wyman and R. Wang, Ann. N. Y. Acad. Sci., 2017, 1398, 108-119.

19 L. Liu, J. Inclusion Phenom. Macrocyclic Chem., 2017, 87, 1-12.

20 B. C. Pemberton, R. Raghunathan, S. Volla and J. Sivaguru, Chem. - Eur. J., 2012, 18, 12178-12190.

21 K. I. Assaf and W. M. Nau, Chem. Soc. Rev., 2015, 44, 394-418.

22 L. Scorsin, J. A. Roehrs, R. R. Campedelli, G. F. Caramori, A. O. Ortolan, R. L. T. Parreira, H. D. Fiedler, A. Acuna, L. García-Río and F. Nome, ACS Catal., 2018, 8, 12067-12079.

23 Y. Jiao, B. Tang, Y. Zhang, J.-F. Xu, Z. Wang and X. Zhang, Angew. Chem., Int. Ed., 2018, 57, 6077-6081.

24 C. Sun, H. Zhang, S. Li, X. Zhang, Q. Cheng, Y. Ding, L.-H. Wang and R. Wang, ACS Appl. Mater. Interfaces, 2018, 10, 25090-25098.

25 R. N. Dsouza, U. Pischel and W. M. Nau, Chem. Rev., 2011, 111, 7941-7980.

26 S. Sinn and F. Biedermann, Isr. J. Chem., 2018, 58, 357-412.

27 G. Ghale, A. G. Lanctôt, H. T. Kreissl, M. H. Jacob, H. Weingart, M. Winterhalter and W. M. Nau, Angew. Chem., Int. Ed., 2014, 53, 2762-2765.

28 X. Ling, E. L. Samuel, D. L. Patchell and E. Masson, Org. Lett., 2010, 12, 2730-2733.

29 V. Sindelar, S. Silvi and A. E. Kaifer, Chem. Commun., 2006, 2185-2187.

30 A. E. Kaifer, W. Li, S. Silvi and V. Sindelar, Chem. Commun., 2012, 48, 6693-6695.

31 E. Masson, M. Raeisi and K. Kotturi, Isr. J. Chem., 2018, 58, 413-434.
32 P. Mukhopadhyay, P. Y. Zavalij and L. Isaacs, J. Am. Chem. Soc., 2006, 128, 14093-14102.

33 W. L. Mock and N. Y. Shih, J. Org. Chem., 1986, 51, 4440-4446.

34 C. Márquez, R. R. Hudgins and W. M. Nau, J. Am. Chem. Soc., 2004, 126, 5806-5816.

35 C. Marquez and W. M. Nau, Angew. Chem., Int. Ed., 2001, 40, 3155-3160.

36 S. S. Thomas and C. Bohne, Faraday Discuss., 2015, 185, 381-398.

37 Z. Miskolczy, J. G. Harangozó, L. Biczók, V. Wintgens, C. Lorthioir and C. Amiel, Photochem. Photobiol. Sci., 2014, 13, 499-508.

38 H. Tang, D. Fuentealba, Y. H. Ko, N. Selvapalam, K. Kim and C. Bohne, J. Am. Chem. Soc., 2011, 133, 20623-20633.

39 Z. Miskolczy and L. Biczók, J. Phys. Chem. B, 2014, 118, 2499-2505.

40 Z. Miskolczy, L. Biczok and I. Jablonkai, Phys. Chem. Chem. Phys., 2017, 19, 766-773.

41 E. Mezzina, F. Cruciani, G. F. Pedulli and M. Lucarini, Chem. - Eur. J., 2007, 13, 7223-7233.

42 Z. Miskolczy and L. Biczók, Phys. Chem. Chem. Phys., 2014, 16, 20147-20156.

43 E. A. Appel, F. Biedermann, D. Hoogland, J. del Barrio, M. D. Driscoll, S. Hay, D. J. Wales and O. A. Scherman, J. Am. Chem. Soc., 2017, 139, 12985-12993.

44 H. E. Hassan, D. Kelly, M. Honick, S. Shukla, A. Ibrahim, D. A. Gorelick, M. Glassman, R. P. McMahon, H. J. Wehring, A. M. Kearns, S. Feldman, M. Yu, K. Bauer and J. B. Wang, J. Clin. Pharmacol., 2017, 57, 151-160.

45 J. B. Wang and J. R. Mantsch, Future Med. Chem., 2012, 4, 177-186.

46 Z.-Y. Yin, L. Li, S.-S. Chu, Q. Sun, Z.-L. Ma and X.-P. Gu, Sci. Rep., 2016, 6, 27129.

47 K. Hirakawa, T. Hirano, Y. Nishimura, T. Arai and Y. Nosaka, J. Phys. Chem. B, 2012, 116, 3037-3044.

48 D. H. Macartney, Isr. J. Chem., 2018, 58, 230-243.

49 A. I. Lazar, J. Rohacova and W. M. Nau, J. Phys. Chem. B, 2017, 121, 11390-11398.

50 I. Ghosh and W. M. Nau, Adv. Drug Delivery Rev., 2012, 64, 764-783.

51 N. Barooah, J. Mohanty, H. Pal and A. C. Bhasikuttan, J. Phys. Chem. B, 2012, 116, 3683-3689.

52 P. Job, Ann. Chim., 1928, 9, 113.

53 Z. Miskolczy, L. Biczók and G. Lendvay, Phys. Chem. Chem. Phys., 2018, 20, 15986-15994.

54 C. J. Li, J. Li and X. S. Jia, Org. Biomol. Chem., 2009, 7, 2699-2703.

55 K. Hirakawa and T. Hirano, Photochem. Photobiol., 2008, 84, 202-208.

56 M. Montalti, A. Credi, L. Prodi and M. T. Gandolfi, Handbook of Photochemistry, CRC Press, Boca Raton, FL, 3rd edn, 2006.

57 R. Hoffmann, W. Knoche, C. Fenn and H.-J. Buschmann, J. Chem. Soc., Faraday Trans., 1994, 90, 1507-1511. 